\title{
Vomiting, electrolyte disturbance, and medications; the perfect storm for acquired long QT syndrome and cardiac arrest: a case report
}

\author{
K. D. Tiver ${ }^{1,2}$, D. Dharmaprani ${ }^{2}$, J. X. Quah ${ }^{1,2}$, A. Lahiri ${ }^{1}$, K. E. Waddell-Smith ${ }^{1}$ and A. N. Ganesan ${ }^{1,2^{*}}$ (1)
}

\begin{abstract}
Background: Acquired long QT syndrome is an important and preventable cause of cardiac arrest. Certain medications and electrolyte disturbance are common contributors, and often coexist. In this case, we report five contributors to cardiac arrest.

Case presentation: This case is of a 51-year-old Caucasian female patient who presented with vomiting associated with hypokalemia and hypomagnesemia. She subsequently received ondansetron and metoclopramide, on the background of chronic treatment with fluoxetine. She then suffered an in-hospital monitored cardiac arrest, with features of long QT and torsades de pointes retrospectively noted on her prearrest electrocardiogram. She was diagnosed with acquired long QT syndrome, and her QT interval later normalized after removal of offending causes.
\end{abstract}

Conclusions: This case highlights the importance of proper consideration prior to prescribing QT prolonging medications, especially in patients who have other risk factors for prolonged QT, such as electrolyte disturbances and pretreatment with QT prolonging medications.

Keywords: Acquired long QT syndrome, Torsades de pointes, Ondansetron, Fluoxetine, Metoclopramide, Hypokalemia, Hypomagnesemia, Renewal theory, Case report

\section{Background}

Long QT syndrome (LQTS) is complex; a genetically, physiologically, and environmentally multifactorial disorder of cardiac ion channels, which leads to abnormal cardiac repolarization. It is, therefore, a cause of ventricular arrhythmias (VAs), in particular torsades de pointes (TdP) and sudden cardiac death (SCD) [1]. Although much of the interest of cardiologists and researchers is focused on genetic LQTS [2], acquired LQTS has also been recognized as being as "risky" as congenital LQTS

\footnotetext{
*Correspondence: anand.ganesan@flinders.edu.au

${ }^{1}$ Department of Cardiology, Level 6, Flinders Medical Centre, Flinders Drive, Bedford Park, SA 5042, Australia

Full list of author information is available at the end of the article
}

[3], and is vastly more common in clinical practice [4]. The prevalence of acquired LQTS is estimated to be $25-30 \%$ in hospitalized populations [5], and most commonly occurs in noncardiac units [6]; however, the true incidence of acquired LQTS causing death is likely to be underreported.

Acquired LQTS is commonly caused by medications [7], electrolyte abnormalities [8], structural heart disease, bradyarrhythmias, starvation, hypothermia, toxins, endocrine disease, liver disease, human immunodeficiency virus infection, and inflammation [9]. It is estimated that $5-7 \%$ of reports of VAs or SCD are due to drug-induced LQTS and TdP [10]. The "multi-hit theory" suggests that more than one risk factor is required to cause clinical or electrocardiographic manifestations of acquired LQTS original author(s) and the source, provide a link to the Creative Commons licence, and indicate if changes were made. The images or other third party material in this article are included in the article's Creative Commons licence, unless indicated otherwise in a credit line to the material. If material is not included in the article's Creative Commons licence and your intended use is not permitted by statutory regulation or exceeds the permitted use, you will need to obtain permission directly from the copyright holder. To view a copy of this licence, visit http://creativecommons.org/licenses/by/4.0/. The Creative Commons Public Domain Dedication waiver (http://creativeco mmons.org/publicdomain/zero/1.0/) applies to the data made available in this article, unless otherwise stated in a credit line to the data. 
[4, 11]. One case series of 11 patients with acquired LQTS revealed all patients had electrolyte abnormalities (including severe hypokalemia), and an average of 2.8 QT prolonging medications administered [12]. In a study of patients admitted to hospital with QT prolongation, $35 \%$ of them received QT prolonging medications, commonly leading to further prolongation of the QT interval [5], indicating a genuinely under-appreciated issue. Many cases of $\mathrm{TdP}$ can be prevented by careful prescribing [13].

\section{Case presentation}

A 51-year-old Caucasian woman presented to the emergency department with several hours of recurrent vomiting, associated with abdominal cramping but no diarrhea. There was no history of unwell contacts or culprit dietary intake, nor was there a history of fevers or any symptoms to suggest another focus of infection. There was no hematemesis or melena. She had no history of illicit drug use. Her past medical history included depression, treated with fluoxetine $20 \mathrm{mg}$, orally, daily. She had no cardiac history, and no significant family history of sudden cardiac death. She was managed with antiemetics, including ondansetron and metoclopramide, and intravenous fluid rehydration with normal saline. Clinical examination demonstrated dehydration, without any apparent cause of the vomiting detectable on clinical examination. Investigations revealed hypokalemia $(2.5 \mathrm{mmol} / \mathrm{L})$ and hypomagnesemia $(0.47 \mathrm{mmol} / \mathrm{L})$, and replacement was commenced. Her initial electrocardiogram (ECG), showed sinus rhythm, with corrected QT interval (QTc) of 680 msecond and had nonsustained runs of TdP and
T wave alternans (Fig. 1). She then had a witnessed cardiac arrest, with the presenting rhythm of polymorphic ventricular tachycardia. She received 30 seconds of chest compressions and was successfully resuscitated without requirement for defibrillation, and recovered to a normal neurologic baseline. Her postresuscitation ECG (Fig. 2) showed a prolonged QT interval. Her postresuscitation venous blood gas showed a $\mathrm{pH}$ of 7.304 , bicarbonate of $20.3 \mathrm{mmol} / \mathrm{L}$, sodium of $142 \mathrm{mmol} / \mathrm{L}$, potassium of $2.6 \mathrm{mmol} / \mathrm{L}$, and glucose of $7.5 \mathrm{mmol} / \mathrm{L}$. The sequence of events is represented in Fig. 3. She underwent further cardiac structural assessment, which was normal. Investigations into alternative causes of the vomiting, including septic screening, liver and kidney function testing, and exclusion of pancreatitis did not reveal a specific cause, and her vomiting resolved spontaneously. She was presumed to have had a viral illness. Her QT normalized after several days of observation, following withdrawal of offending medications and replacement of electrolytes, and she was discharged home with a diagnosis of acquired long QT syndrome. At follow up clinic review at 2 months and at 12 months, she remained asymptomatic with a normal QT interval, and will have ongoing follow-up.

\section{Discussion}

This case report highlights the "perfect storm" of electrolyte disturbance (potassium, magnesium) and medication effects (fluoxetine, ondansetron, and metoclopramide), leading to acquired long QT syndrome and cardiac arrest.

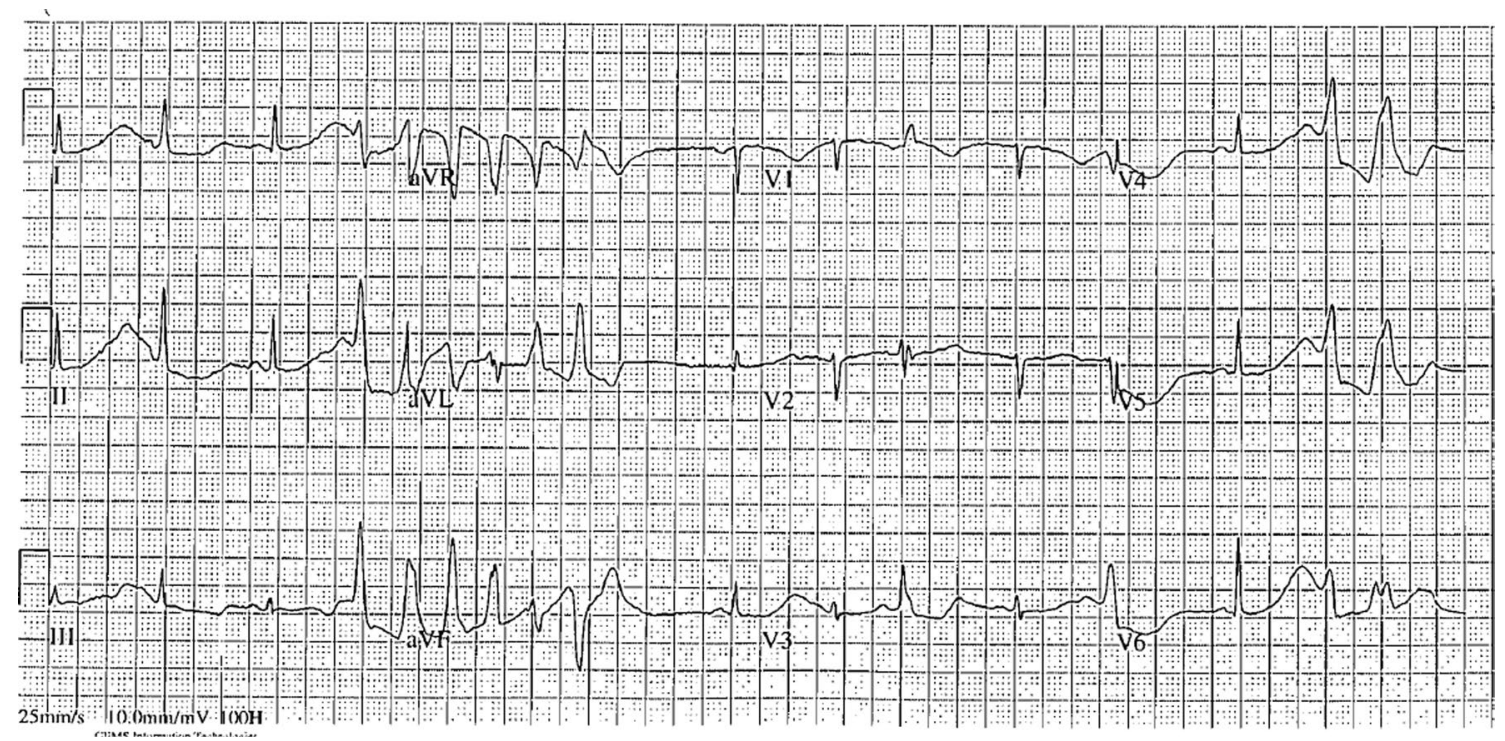

Fig. 1 Electrocardiogram just prior to cardiac arrest, demonstrating very long QT interval, T wave alternans, and short runs of torsades de pointes 


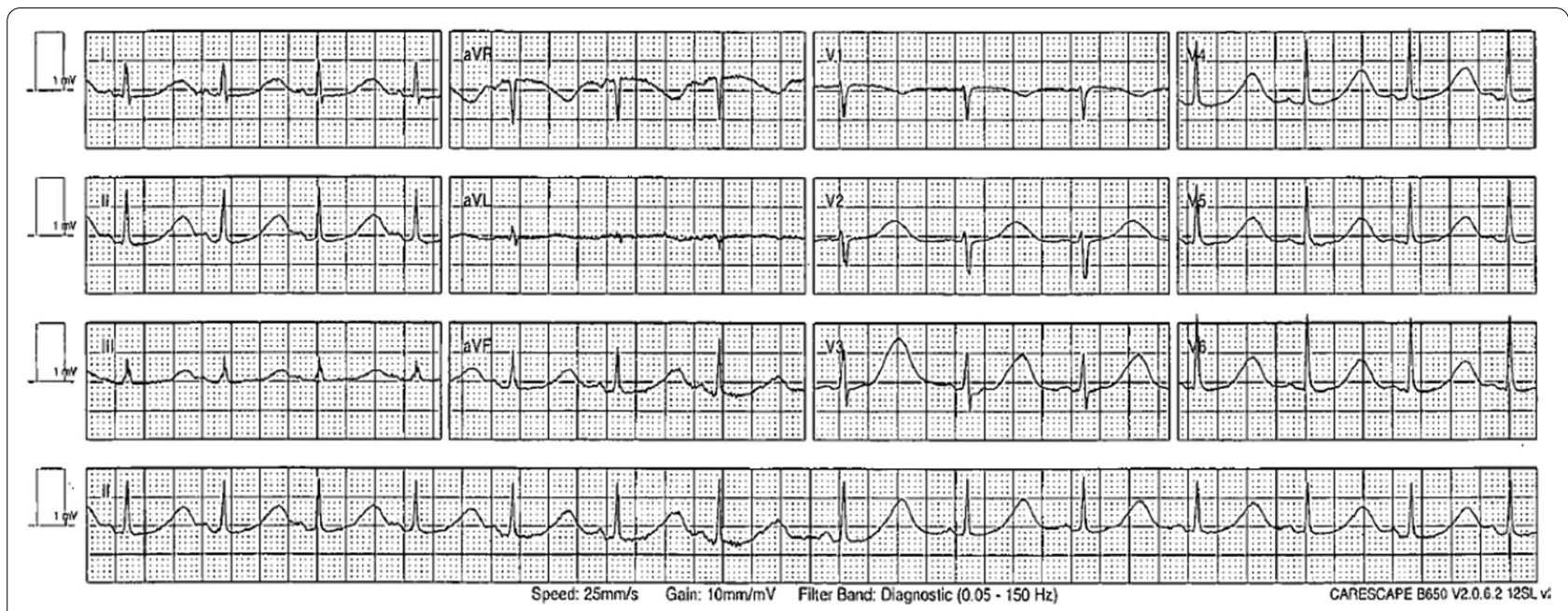

Fig. 2 Electrocardiogram following resuscitation, demonstrating significantly prolonged QT interval

Ondansetron is known to prolong the QT interval in a dose-dependent manner [14], it is recommended to be used with caution in patients who may develop prolongation of QTc, such as patients with electrolyte abnormalities [15]. Of note, it is very likely for this scenario to occur, as vomiting is not only the indication for administering ondansetron, but is also a risk factor for electrolyte abnormalities and, therefore, QT prolongation.

Fluoxetine is also known to cause prolonged QT interval. The product information suggests it should be used with caution with other clinical conditions that predispose to arrhythmias, such as hypokalemia or hypomagnesemia [16]. Based on a recent comparative review, fluoxetine was reported to have one of the lower risk profiles of its class for causing QT prolongation, along with sertraline and fluvoxamine [17]. Prescription of selective serotonin reuptake inhibitors (SSRIs) is so common in the community that even a rare side effect will be observed. In 2018-2019, 17.1\% of the Australian population received a mental health-related prescription, $70.9 \%$ of these were antidepressants, and SSRIs are first line antidepressants [18]. These rates are increasing with time, indicating a growing percentage of our population with a baseline risk factor for QT prolongation, even prior to acute illness.

Although metoclopramide on its own is not listed as a QT prolonging medication, and no warnings about QT prolongation exist on its product information, there is evidence that it can contribute to QT prolongation. There are reports of important pharmacokinetic and pharmacodynamic drug-drug interactions that can contribute to QTc prolongation, especially with ondansetron [19]. In addition, metoclopramide has been mechanistically shown to change QT dynamics [20], as well as showing a signal in epidemiological research [21]. It has been added to crediblemeds.org as a "TdP conditional drug" [22], meaning that in combination with other medications, it may prolong the QT interval and increase the risk of TdP.

Despite the good clinical outcome in this case, mortality of cardiac arrest survivors remains high, even when the underlying cause was transient or correctable [23]. Some authors have suggested implantable defibrillators may beneficial, even in this situation of an acquired proarrhythmic state [24]. The patient presented in this case was assessed to have acquired long QT syndrome, rather than congenital long QT syndrome based on the normalization of the QT interval following removal of the five precipitating factors. Following removal of the precipitants, the patient's Schwartz score for diagnosis of congenital LQTS was 0 , indicating low risk of the congenital condition. Given the tendency demonstrated towards prolonged QT with precipitating conditions, however, she will have ongoing clinical electrophysiology review to monitor her symptoms and QT interval.

The patient in this case feels she did not understand what was happening to her, or why it was happening. She does fear another cardiac arrest, which is impacting on her life.

In this case, we make the observation that $\mathrm{TdP}$ is selflimited after a number of seconds in the first ECG, with no patient symptoms, and subsequently only a few minutes later, TdP is prolonged, leading to the devastating consequence of cardiac arrest. We do not currently understand what causes TdP to self-terminate, or to continue [1]. Perhaps this could be understood by studying $\mathrm{TdP}$ from a wavefront dynamic perspective, given the observations that QRS morphology often abruptly switches from positive to negative during the warm-up 


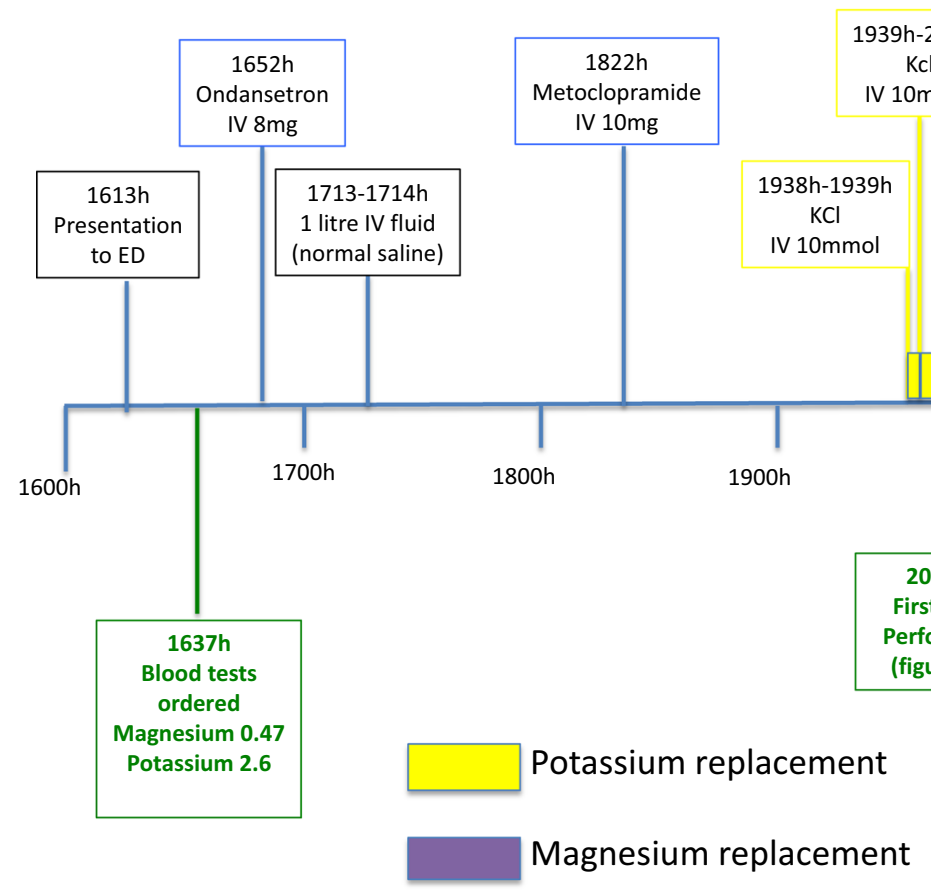

Fig. 3 Fishbone diagram of presentation, investigations, medications, and infusions administered. ED emergency department, $\mathrm{KCl}$ potassium chloride, $\mathrm{I}$ intravenous, $\mathrm{MgSO}_{4}$ magnesium sulfate

phenomenon [11]. A characteristic feature of TdP is that the vast majority of polymorphic ventricular arrhythmia episodes are self-terminating, as observed in this case. The mechanisms underlying this repetitive pattern of self-termination, and what distinguishes TdP from more sustained forms of ventricular fibrillation, are currently unclear. Our group has recently extensively been studying arrhythmia self-termination in atrial fibrillation and ventricular fibrillation. In self-terminating epochs, it appears that the rate of reentrant rotor formation and destruction is much slower compared with more sustained arrhythmia epochs. We have developed a novel statistical framework based on renewal theory to characterize these differences [25-27]. It would be of significant interest to extend these approaches to the clinical scenario of TdP, which would allow us to gain insight into the optimal prophylactic and treatment strategies for this form of arrhythmia.

\section{Conclusion}

This case serves as an important reminder that vomiting leads to both electrolyte disturbances and the prescription of antiemetics, which here led to a quadruple hit (hypokalemia, hypomagnesemia, ondansetron, metoclopramide) causing TdP and cardiac arrest. SSRIs are so commonly prescribed, that 1 in 6 patients may have this preexisting risk factor for $\mathrm{TdP}$, as this patient did, contributing to the multiple hits required for clinical manifestations of acquired LQTS. This case occurred in a monitored hospital emergency room, and the patient had a favorable outcome. However, there is a genuine risk of fatal outcomes from a similar situation for a patient in the ambulatory setting, where patients can present with vomiting and are often given antiemetics without performing biochemistry or clinical observation.

\section{Take home message}

This case illustrates the clinical teaching point that care must be taken to avoid multiple "hits" that contribute to QT prolongation. The commonly available antiemetics have all been associated with QT prolongation to some extent, so if antiemetic therapy is needed in the future for this patient, care must be taken to check electrolytes and monitor the QT interval during treatment. In such a patient, SSRI treatment in the future should be considered on a risk versus benefit basis. If indicated, fluoxetine, along with sertraline and fluvoxamine are least QT prolonging SSRIs. These may be given, but careful attention must be paid to monitoring the QT interval and avoiding other risk factors for QT prolongation.

\section{Abbreviations}

LQTS: Long QT syndrome; VA: Ventricular arrhythmias; TdP: Torsades de pointes; SCD: Sudden cardiac death; ECG: Electrocardiogram; QTc: Corrected QT 
interval; SSRI: Selective serotonin reuptake inhibitor; ED: Emergency department; $\mathrm{KCl}$ : Potassium chloride; $\mathrm{MgSO}_{4}$ : Magnesium sulfate.

\section{Acknowledgements}

Not applicable.

\section{Authors' contributions}

KT wrote the manuscript; DD, JQ, AL, KWS, and AG had scientific contribution and input into the final manuscript. All authors read and approved the final manuscript.

\section{Funding}

Nil funding required.

\section{Availability of data and materials}

Not applicable.

\section{Declarations}

\section{Ethics approval and consent to participate}

Not required.

\section{Consent for publication}

Written informed consent was obtained from the patient for publication of this case report and any accompanying images. A copy of the written consent is available for review by the Editor-in-Chief of this journal.

\section{Competing interests}

The authors declare that they have no competing interests.

\section{Author details}

${ }^{1}$ Department of Cardiology, Level 6, Flinders Medical Centre, Flinders Drive, Bedford Park, SA 5042, Australia. ${ }^{2}$ College of Medicine and Public Health, Flinders University, Bedford Park, Australia.

Received: 24 May 2021 Accepted: 22 November 2021

Published online: 11 January 2022

\section{References}

1. Schwartz PJ, Crotti L, Insolia R. Long-QT syndrome: from genetics to management. Circ Arrhythm Electrophysiol. 2012;5(4):868-77.

2. Waddell-Smith KE, Skinner JR, C.G.C.W.G. members of the. Update on the diagnosis and management of familial long QT syndrome. Heart Lung Circ. 2016:25(8):769-76.

3. Wong LC, Behr ER. Acquired long QT syndrome: as risky as congenital long QT syndrome? Europace. 2012;14(3):310-1.

4. El-Sherif N, Turitto G, Boutjdir M. Acquired long QT syndrome and electrophysiology of Torsade de Pointes. Arrhythm Electrophysiol Rev. 2019;8(2):122-30

5. Tisdale JE, et al. Prevalence of QT interval prolongation in patients admitted to cardiac care units and frequency of subsequent administration of QT interval-prolonging drugs. Drug Saf. 2012;35(6):459-70.

6. Yu H, et al. Acquired long QT syndrome in hospitalized patients. Heart Rhythm. 2017;14(7):974-8.

7. Kannankeril P, Roden DM, Darbar D. Drug-induced long QT syndrome. Pharmacol Rev. 2010;62(4):760-81.

8. El-Sherif N, Turitto G. Electrolyte disorders and arrhythmogenesis. Cardiol J. 2011;18(3):233-45.

9. Lazzerini PE, Capecchi PL, Laghi-Pasini F. Long QT syndrome: an emerging role for inflammation and immunity. Front Cardiovasc Med. 2015;2:26.

10. Molokhia M, et al. Case ascertainment and estimated incidence of drug-induced long-QT syndrome: study in Southwest France. Br J Clin Pharmacol. 2008;66(3):386-95.

11. Drew BJ, et al. Prevention of torsade de pointes in hospital settings: a scientific statement from the American Heart Association and the American College of Cardiology Foundation. Circulation. 2010;121(8):1047-60.

12. Digby GC, et al. Acquired long QT interval: a case series of multifactorial QT prolongation. Clin Cardiol. 2011;34(9):577-82.
13. Thomas SH, Behr ER. Pharmacological treatment of acquired QT prolongation and torsades de pointes. Br J Clin Pharmacol. 2016;81 (3):420-7.

14. MIMS online. Ondansetron MIMS Full Product Information. 2020. https:// www-mimsonline-com-au.salus.idm.oclc.org/Search/FullPl.aspx?Modul eName=Product\%20Info\%26searchKeyword=ondansetron\%26Pre viousPage $=\sim /$ Search/QuickSearch. aspx\%26SearchType =\%26ID =90140 001_2\#Precautions8812

15. Administration TG. Ondansetron consumer medicines information. 2021. https://www.ebs.tga.gov.au/ebs/picmi/picmirepository.nsf/pdf?OpenA gent\&id=CP-2009-CMI-00741-3\&d=202104011016933.

16. Administration TG. Australian product information APO-fluoxetine. 2018. https://www.ebs.tga.gov.au/ebs/picmi/picmirepository.nsf/pdf?OpenA gent\&id=CP-2010-PI-01265-3.

17. Funk KA, Bostwick JR. A comparison of the risk of QT prolongation among SSRIs. Ann Pharmacother. 2013;47(10):1330-41.

18. Australian Institute for Health and Welfare. Mental health services in Australia. 2021. https://www.aihw.gov.au/reports/mental-health-services/ mental-health-services-in-australia/report-contents/mental-health-relat ed-prescriptions.

19. Fernandes FM, et al. Assessment of the risk of QT-interval prolongation associated with potential drug-drug interactions in patients admitted to intensive care units. Saudi Pharm J. 2019;27(2):229-34.

20. Ellidokuz E, Kaya D. The effect of metoclopramide on QT dynamicity: double-blind, placebo-controlled, cross-over study in healthy male volunteers. Aliment Pharmacol Ther. 2003;18(1):151-5.

21. Sarganas $G$, et al. Epidemiology of symptomatic drug-induced long QT syndrome and Torsade de Pointes in Germany. Europace. 2014;16(1):101-8

22. CredibleMeds.com. CredibleMeds. 2014. https://www.crediblemeds.org/ blog/two-medicines-added-tdp-conditional-risk-list/.

23. Al-Khatib SM, et al. 2017 AHA/ACC/HRS guideline for management of patients with ventricular arrhythmias and the prevention of sudden cardiac death: a report of the American College of Cardiology/American Heart Association Task Force on Clinical Practice Guidelines and the Heart Rhythm Society. Circulation. 2018;138(13):e272-391.

24. Monnig G, et al. Role of implantable cardioverter defibrillator therapy in patients with acquired long QT syndrome: a long-term follow-up. Europace. 2012;14(3):396-401.

25. Dharmaprani $D$, et al. M/M/infinity birth-death processes - a quantitative representational framework to summarize and explain phase singularity and wavelet dynamics in atrial fibrillation. Front Physiol. 2020;11:616866.

26. Dharmaprani $D$, et al. Renewal theory as a universal quantitative framework to characterize phase singularity regeneration in mammalian cardiac fibrillation. Circ Arrhythm Electrophysiol. 2019;12(12):e007569.

27 Quah JX, Dharmaprani D, Lahiri A, Tiver K, Ganesan AN. Reconceptualising atrial fibrillation using renewal theory: a novel approach to the assessment of atrial fibrillation dynamics. Arrhythm Electrophysiol Rev. $2021 ; 10: 77-84$

\section{Publisher's Note}

Springer Nature remains neutral with regard to jurisdictional claims in published maps and institutional affiliations.

Ready to submit your research? Choose BMC and benefit from:

- fast, convenient online submission

- thorough peer review by experienced researchers in your field

- rapid publication on acceptance

- support for research data, including large and complex data types

- gold Open Access which fosters wider collaboration and increased citations

- maximum visibility for your research: over $100 \mathrm{M}$ website views per year

At BMC, research is always in progress.

Learn more biomedcentral.com/submissions 